\title{
Correction to: Using Semi-Markov Chains to Solve Semi-Markov Processes
}

\section{Bei $\mathrm{Wu}^{1} \cdot$ Brenda Ivette Garcia Maya ${ }^{2} \cdot$ Nikolaos Limnios $^{2}$}

Published online: 7 November 2020

(C) Springer Science+Business Media, LLC, part of Springer Nature 2020

\section{Correction to: Methodology and Computing in Applied Probability https://doi.org/10.1007/s11009-020-09820-y}

The original version of this article contained mistakes and the author would like to correct them.

In the published version of this article, in the definition of the norm of $\mathbf{A}(t)$ and Propositions 2 and 3, the norm is missed. The right statements are listed as follows:

The definition of the norm of $\mathbf{A}(t)$ in Page 7 should read:

Consider now the function $\mathrm{A}_{i j}(t)$ defined on $E \times E \times \mathbb{R}$ such that $\mathrm{A}_{i j}(t)=0$ for all $i, j \in E$ and $t<$ 0 , and define the following norm on $[0, t]$ :

$$
\|\mathbf{A}\| \mid(t)=\sup _{0 \leq u \leq t}\|\mathbf{A}\|(u)
$$

Proposition 2 in Page 8 should read:

Proposition 2. The distance between transition function matrices, $\widetilde{\mathbf{P}}_{h}(t)$ and $\mathbf{P}(t)$, verifies the following inequality

$$
\left\|\widetilde{\mathbf{P}}_{h}-\mathbf{P}\right\| \mid(t) \leq \min \left\{\kappa\left(\widetilde{\mathbf{Q}}_{h}, \mathbf{Q}\right)(t), \kappa\left(\mathbf{Q}, \widetilde{\mathbf{Q}}_{h}\right)(t)\right\}
$$

The online version of the original article can be found at https://doi.org/10.1007/s11009-020-09820-y

Bei Wu

315562327@qq.com

1 School of Management and Economics, Beijing Institute of Technology, Beijing 100081, China

2 Université de Technologie de Compiègne, Sorbonne University, Paris, France 
where

$$
\kappa\left(\widetilde{\mathbf{Q}}_{h}, \mathbf{Q}\right)(t)=s^{2} \cdot\left\|\boldsymbol{\Psi}_{h}\right\|(t) \cdot\left\|\widetilde{\mathbf{Q}}_{h}-\mathbf{Q}\right\| \mid(t) \cdot(2\|\boldsymbol{\psi}\|(t)+1) .
$$

Proposition 3 in Page 8 should read:

Proposition 3. If for a fixed time $t>0$, the matrices $\left(\mathbf{I}-\widetilde{\mathbf{P}}_{h}(t)\right)$ and $(\mathbf{I}-\mathbf{P}(t))$ are nonsingular, then

$$
\left\|\widetilde{\mathbf{P}}_{h}-\mathbf{P}\right\| \mid(t) \leq \min \left\{\lambda\left(\widetilde{\mathbf{Q}}_{h}, \mathbf{Q}\right)(t), \lambda\left(\mathbf{Q}, \widetilde{\mathbf{Q}}_{h}\right)(t)\right\}
$$

where

$$
\lambda\left(\widetilde{\mathbf{Q}}_{h}, \mathbf{Q}\right)(t)=\delta_{h} \bullet s^{2} \cdot \max _{i, j}[\mathbf{I}-\mathbf{Q}(t)]^{-1}(i, j) \cdot\left(2 \max _{i, j}\left[\mathbf{I}-\widetilde{\mathbf{Q}}_{h}(t)\right]^{-1}(i, j)+1\right)
$$

The original article has been corrected.

Publisher's Note Springer Nature remains neutral with regard to jurisdictional claims in published maps and institutional affiliations. 